\title{
ORDINARY LEAST SQUARE VS FIXED EFFECT REGRESSION MODEL: Studi Empirik Determinan Kebijakan Dividen Pada Perusahaan-perusahaan yang Terdaftar di Bursa Efek Indonesia (BEI)
}

\author{
Caecilia Wahyu E.R. \\ Universitas Sanata Ddharma Yogyakarta
}

\begin{abstract}
This research analyzes determinants of corporate dividend policy in Indonesia Stock Exchange (IDX). This research hypothesizes that four financial ratios, which are dividend yield, ROA (return on assets), leverage and $P B V$ (price-to-book value ratio) are determinants of corporate dividend policy.

Samples of 25 firms, which are included in many sectors, are all fulfilling data completeness criteria. Research periods are from 2002 until 2006. A balanced panel data study technique is employed to analyze determinants of corporate dividend policy in Indonesia Stock Exchange (IDX). There are two models to estimate regression model used in this research, that is usual Ordinary Least Square (OLS) regression model and the Fixed Effects (FE) or Least Squares Dummy Variable (LSDV) regression model.

The study documented that dividend yield, return on assets and leverage have positive effect to dividend payment significantly based on OLS model. Otherwise FE model found dividend yield is the only variable that statistically significant influence dividend payment. The better model to predict determinants of corporate dividend policy is FE model. FE model has higher R-squared value and Durbin-Watson d value than OLS model. In addition, FE model can explain this issue clearly and specifically.
\end{abstract}

Keywords: dividend policy, dividend yield, ROA, leverage, $P B V$.

\section{PENDAHULUAN}

Kebijakan dividen merupakan salah satu topik yang banyak diperdebatkan dalam literatur keuangan dan masih tetap dipertahankan menduduki posisi utama dalam teori keuangan perusahaan sampai sekarang ini. Yang dimaksud dengan kebijakan dividen adalah keputusan apakah laba yang diperoleh perusahaan akan dibagikan kepada para pemegang saham sebagai dividen atau akan diinvestasikan kembali dalam perusahaan dalam bentuk laba ditahan (Brigham, 1999: 449). Apabila perusahaan memilih untuk membagikan laba sebagai dividen maka akan mengurangi laba yang ditahan, dan selanjutnya mengurangi total sumber dana internal, demikian sebaliknya. Dengan demikian kebijakan dividen ini harus dianalisis dalam kaitannya dengan keputusan pendanaan atau penentuan struktur modal secara keseluruhan.

Isu kebijakan dividen sampai sekarang ini masih tetap tak terpecahkan. Garis pedoman yang jelas untuk kebijakan dividen yang optimal belum juga muncul meskipun banyak literatur.yang mengulas tentang kebijakan dividen ini. Kita masih belum memiliki penjelasan yang dapat 
diterima mengenai perilaku dividen perusahaan yang diamati. Selain itu pula kita masih belum memahami secara menyeluruh faktor-faktor yang mempengaruhi kebijakan dividen dan pola interaksi faktor-faktor tersebut. Hal inilah yang disebut sebagai dividend puzzle dalam literatur keuangan (Naceur et al, 2006: 1-2). Beberapa hipotesis telah diajukan dalam beberapa penelitian tetapi masih belum mampu memberikan jawaban terhadap dividend puzzle tersebut.

Beberapa penelitian telah banyak dilakukan dengan tujuan untuk menyelidiki faktor-faktor yang menjadi determinan perusahaan dalam melakukan kebijakan dividennya. Hal ini dilakukan dengan tujuan agar perusahaan dapat menentukan kebijakan dividen yang optimal. Kebijakan dividen yang optimal mencerminkan keseimbangan antara dividen saat ini dan pertumbuhan dividen di masa mendatang sehingga dapat memaksimalkan harga saham perusahaan sehingga pada akhirnya dapat meningkatkan nilai perusahaan.

Alli et al (1993) menguji tentang determinan kebijakan dividen perusahaan dengan menggunakan faktor analisis. Hasil penelitian menunjukkan bahwa enam faktor (dimensi) yang mempengaruhi kebijakan dividen secara signifikan yaitu issuance cost, pecking order, dividend stability, tax \& agency cost effect, financial slack, dan capital structure flexibility. Temuan lainnya adalah terdapat hubungan yang positif antara dividend payout ratio dan faktor-faktor yang merupakan representasi dari stabilitas dividen, biaya pajak dan keagenan, dan fleksibilitas struktur modal. Namun dividen tidak memberikan sinyal yang efektif terhadap volatilitas aliran kas.

Kemudian Baker \& Powell (2000) memberikan temuannya atas hasil survei terhadap manajer perusahaan di Amerika yang terdaftar di NYSE (New York Stock Exchange) bahwa determinan kebijakan dividen perusahaan yang paling penting adalah tingkat earning saat ini dan earning yang diharapkan di masa mendatang, dan pola kontinyuitas dividen yang lalu. Faktor yang paling penting mempengaruhi kebijakan dividen pada tahun 1983 dengan cara survei sangat menyerupai hasilnya dengan hasil survei ini. Ketika dilakukan secara bersama-sama, temuannya menunjukkan bahwa sedikit perubahan pada determinan dividen terjadi sepanjang waktu.

Baker, Veit \& Powell (2001) melaporkan hasil surveinya terhadap 188 manajer perusahaan yang terdaftar di Nasdaq bahwa determinan yang paling penting dalam kebijakan dividen adalah pola dividen yang lalu, stabilitas earning, tingkat earning saat ini dan earning yang diharapkan di masa mendatang. Faktor-faktor yang dianggap paling penting bagi manajer perusahaan di Nasdaq maupun di NYSE (survei sebelumnya) sama. Kebanyakan manajer masih membuat kebijakan dividen konsisten dengan model dan hasil survei Lintner.

Naceur, Goaied, dan Belanes (2006) mengkaji kebijakan dividen dari 48 perusahaan yang terdaftar di TSE (Tunisian Stock Exchange), dan menganalisis apakah para manajernya melakukan smoothing (manipulasi) terhadap dividennya, diuji dengan menggunakan model Lintner (asumsi kebijakan dividen bersifat dinamik). Selain itu mengkaji determinan penting yang mendorong manajer menentukan kebijakan dividen. Hasil riset menunjukkan bahwa perusahaan Tunisia mengandalkan pada earning saat ini dan dividen yang lalu guna mengatur pembayaran dividennya.

Adapun penelitian ini merupakan replikasi dari penelitian Naceur et al (2006) dengan menggunakan sampel perusahaanperusahaan yang terdaftar di Bursa Efek Indonesia. Tujuan penelitian ini adalah untuk mengetahui faktor-faktor penting apa yang mempengaruhi kebijakan dividen (diproksi dengan DPS, dividend per-share). 
Temuan dari penelitian empiris ini diharapkan mampu memberikan sumbangan dalam literatur keuangan dan pembuatan kebijakan dividen bagi manajer perusahaan secara optimal.

\section{TINJAUAN PUSTAKA DAN PERUMUSAN HIPOTESIS Signalling Theory}

Menurut Alli et al (1993) meskipun sampai saat ini masih menjadi perdebatan mengenai dividen benar-benar merupakan sinyal tentang informasi earning perusahaan saat ini maupun di masa mendatang tetapi ada sejumlah studi yang dilakukan (Aharony \& Swary, Asquith \& Mullins, dan Pettit) menunjukkan bahwa dividen mengandung informasi. Menurut signalling theory perusahaan lebih suka memiliki dividend yield yang tinggi (yang dihitung dengan cara dividend per share (DPS) dibagi dengan harga saham penutupan pada akhir periode). Semakin tinggi dividend yield yang dimiliki perusahaan menunjukkan sinyal yang positif bagi pasar karena perusahaan dianggap mampu membayarkan dividen yang lebih besar. Berdasarkan uraian ini maka dapat diduga bahwa semakin besar dividend yield perusahaan maka semakin besar dividen yang dibayarkan (diproksi dengan DPS).

H1: Dividend yield berpengaruh positif terhadap DPS

\section{Pecking Order Theory}

Menurut Miller dan Modigliani (1961) nilai perusahaan ditentukan oleh earning power dari asetnya dan kebijakan investasi. Oleh karena itu suatu perusahaan berusaha keras memiliki kebijakan investasi yang optimal. Untuk menciptakan nilai perusahaan tak dapat dilakukan hanya dengan mengubah kombinasi kebijakan dividen dan laba ditahan. Jadi perusahaan dengan profitabilitas yang tinggi mampu menanggung free cash flow yang semakin besar dan kesempatan investasi baru. Menurut Myers dan Majluf, 1984 (dikutip dalam Jensen et al, 1992: 250) berdasarkan pecking order theory perusahaan lebih suka menggunakan internal financing dulu, baru berhutang, kemudian external equity. Semakin profitabel perusahaan maka internal financing dimungkinkan untuk dipakai lebih dulu guna membayarkan dividen yang lebih besar. Profitabilitas perusahaan diproksi dengan ROA (return on assets), sehingga hipotesis yang diajukan adalah ROA berpengaruh positif terhadap pembayaran dividen. Berdasarkan uraian ini maka dapat diduga bahwa semakin besar ROA perusahaan semakin besar dividen yang dibayarkan

H2: ROA berpengaruh positif terhadap DPS

\section{Agency Theory}

Menurut Jensen (1986) dan Stulz

(1990) dalam teori keagenan, hutang memainkan peranan yang disipliner: dengan menaikkan tingkat hutang, maka free cash flow akan berkurang. Di samping itu pemegang saham kemungkinan akan melakukan ekspropriasi kemakmuran dengan membayarkan dividen untuk diri mereka sendiri atas biaya kreditur, dan kreditur mencoba untuk mengatasinya dengan melakukan indentures restriction (pembatasan gerak terhadap penggunaan hutang tersebut) terhadap perusahaan selaku debitur (Alli et al, 1993). Oleh karena itu sebagai konsekuensinya, perusahaan dengan rasio hutang yang tinggi seharusnya membayar dividen yang lebih rendah, karena sebagian pendapatannya digunakan untuk membayar hutang. Proksi yang digunakan untuk rasio hutang perusahaan adalah leverage, dan ini diduga berpengaruh negatif terhadap pembayaran dividen. Berdasarkan uraian ini maka dapat diduga bahwa semakin besar leverage maka semakin kecil dividen yang dibayarkan. 
H3: Leverage berpengaruh negatif terhadap DPS

\section{Residual Dividend Theory}

Menurut Brigham \& Gapenski (1999: 450) teori ini mengandung arti bahwa dividen dibayarkan karena adanya sisa dari pendapatannya (laba) setelah dikurangi laba ditahan yang digunakan untuk mendanai investasi baru. Oleh karena itu dapat dihipotesiskan bahwa perusahaan dengan kesempatan investasi yang besar akan membutuhkan dukungan finansial yang kuat, atau dengan kata lain lebih suka untuk menahan laba daripada mendistribusikannya. Proksi yang digunakan untuk kesempatan investasi adalah price-to-book value ratio (PBV), dan ini diduga berpengaruh negatif terhadap pembayaran dividen. Berdasarkan uraian ini maka dapat diduga bahwa semakin besar kesempatan investasi maka semakin kecil dividen yang dibayarkan.

H4: PBV berpengaruh negatif terhadap DPS

\section{METODA PENELITIAN}

Jenis Data, Sumber dan Pengumpulannya Penelitian ini menggunakan data sekunder. Data sekunder diperoleh dari Indonesian Capital Market Directory (ICMD). Jumlah perusahaan pada periode penelitian, tahun 2002-2006 ada sejumlah 333-343 prsh yg listed di BEI tetapi hanya 25 perusahaan yang digunakan sebagai sampel penelitian karena yang memenuhi syarat kelengkapan data hanya 25 perusahaan, yang terdiri dari berbagai jenis perusahaan. Dengan demikian jumlah observasi ada sebanyak 125. Adapun data yang digunakan dalam penelitian ini berhubungan dengan data tahunan DPS (dividend per-share), dividend yield, ROA (return on assets), leverage, dan PBV (price-to-book value ratio). Studi ini menggunakan panel data yang balanced.
Definisi Operasional dan Pengukuran Variabel

Dividend per-share (DPS)

Dividend per-share adalah sebagian dari pendapatan perusahaan setelah dikurangi pajak dan dikurangi dividen yang menjadi hak bagi pemegang saham preferen (apabila ada), dalam bentuk Rupiah perlembar saham, yang menjadi hak yang diterima para pemegang saham atas saham yang dimilikinya (apabila membagikan dividen). Variabel ini diukur dengan menggunakan rasio antara dividen bagi pemegang saham biasa dan jumlah lembar saham yang beredar.

Dividend yield (Div_yield)

Dividend yield adalah yield (hasil) atas dividen bagi para pemegang saham biasa. Variabel ini diukur dengan menggunakan rasio antara dividend pershare dibagi harga saham penutupan pada akhir periode.

Return on Assets (ROA)

Return on Assets merupakan return bersih sesudah pajak yang diperoleh perusahaan atas aset yang digunakannya. Variabel ini diukur dengan menggunakan rasio antara return bersih sesudah pajak dengan total asetnya.

Leverage (Lev)

Leverage adalah persentase hutang yang dimiliki perusahaan dari total asetnya. Variabel ini diukur dengan menggunakan rasio antara total hutang dengan total asetnya.

Price-to-book value (PBV)

Price-to-book value merupakan harga saham pada saat penutupan pada akhir periode dibagi earning per share

\section{Teknik Pengujian Hipotesis}

Studi ini menggunakan data panel dengan time series yang pendek. Menurut Verbeek (2004: 310) keuntungan regresi dengan menggunakan data panel dibandingkan dengan data runtun waktu atau 
lintas sektoral adalah kemampuan regresi data panel dalam mengidentifikasi parameter-parameter regresi secara pasti tanpa membutuhkan asumsi restriksi atau kendala. Menurut Insukindro et al (2001: 150) kesulitan utama dari model panel adalah bahwa faktor pengganggu akan berpotensi mengandung gangguan yang disebabkan karena penggunaan observasi runtun waktu, lintas sektoral, serta gabungan keduanya. Menurut Pindyck dan Rubinfeld, 1998 (dikutip dalam Insukindro et al, 2001: 150) dalam ekonometri minimal ada tiga prosedur estimasi data panel guna mengatasi berbagai permasalahan penggabungan dua jenis observasi tersebut yaitu pertama dengan penggabungan semua data serta mengestimasi regresi dengan metoda OLS untuk seluruh set data. Kedua dengan didasarkan pemahaman bahwa menghilangkan satu variabel penjelas akan menyebabkan berubahnya intersep runtun waktu dan lintas sektoral. Prosedur ketiga adalah mencoba meningkatkan efisiensi estimasi parameter dengan cara mengatasi gangguan yang disebabkan karena penggunaan data runtun waktu dan lintas sektoral.

Adapun model regresi yang digunakan dalam studi ini adalah sebagai berikut:

$D_{P S} S_{i t}=\beta_{1}+\beta_{2} D Y_{i t}+\beta_{3} R_{\text {OA }}+\beta_{4} L_{\text {EV }}$ it $+\beta_{5} \mathbf{P B V}_{\text {it }}+\mu_{\mathrm{it}}$
Keterangan:

DPS $_{\text {it }}=$ dividend per-share perusahaan $\mathrm{i}$ pada perioda $\mathrm{t}$.

DY $_{\text {it }}=$ dividend yield perusahaan $\mathrm{i}$ pada perioda t.

$\mathbf{R O A}_{\mathbf{i t}}=$ return on assets perusahaan i pada perioda $\mathrm{t}$.

$\mathbf{L E V}_{\text {it }}=$ leverage perusahaan i pada perioda t.

$\mathbf{P B V}_{\text {it }}=$ price - to - book value perusahaan $\mathrm{i}$ pada perioda t.

$\mu_{\mathrm{it}}=$ disturbance error .

$\mathrm{i} \quad=1,2, \ldots ., 25$

$\mathrm{t} \quad=1,2,3,4,5$

Model regresi ini akan diestimasi dengan menggunakan pendekatan yang memakai variabel boneka (Fixed Effect Model), tetapi sebelumnya digunakan pendekatan Ordinary Least Square biasa. Hal ini dimaksudkan agar dapat diketahui hasil estimasi masing-masing pendekatan dan dapat diketahui pendekatan mana yang mampu memberikan model regresi yang terbaik dari pengujian ini.

\section{HASIL DAN PEMBAHASAN}

Berikut ini merupakan hasil rangkuman lima rasio keuangan perusahaan untuk seluruh sampel (25 perusahaan) selama periode pengamatan (lima tahun) dalam tabel deskripsi statistika. 
Tabel 1: Statistika Deskriptif

\begin{tabular}{lrrrrr}
\hline & DPS & DIV_YIELD & ROA & LEV & PBV \\
\hline Mean & 301.76 & 4.51 & 0.11 & 0.44 & 2.32 \\
Median & 63.00 & 2.99 & 0.09 & 0.42 & 1.42 \\
Maximum & 3342.00 & 45.35 & 0.40 & 0.81 & 21.26 \\
Minimum & 1.00 & 0.01 & -0.02 & 0.04 & 0.13 \\
Std. Dev. & 674.91 & 5.17 & 0.08 & 0.19 & 2.90 \\
Skewness & 3.23 & 4.46 & 1.46 & -0.08 & 3.82 \\
Kurtosis & 12.73 & 33.09 & 5.16 & 2.24 & 20.76 \\
Jarque-Bera & 710.32 & 5130.22 & 68.55 & 3.15 & 1947.66 \\
Probability & 0.00 & 0.00 & 0.00 & 0.21 & 0.00 \\
& & & & & \\
Sum & 37720.00 & 563.35 & 13.36 & 54.48 & 290.02 \\
Sum Sq. Dev. & 56482773 & 3310.05 & 0.89 & 4.59 & 1039.12 \\
& & & & & 125 \\
Observations & 125 & 125 & 125 & 25 & 25 \\
Cross sections & 25 & 25 & 25 & & \\
\hline
\end{tabular}

\section{Pengujian Hipotesis} Uji Stasioner

Tahap pertama sebelum melakukan pengujian hipotesis yang menyatakan bahwa pembayaran dividen (diproksi dengan DPS) dipengaruhi oleh variable dividend yield, ROA, leverage, dan price-to-book value (PBV) adalah melakukan uji stasioner. Uji stasioner adalah uji terhadap stabilitas (konstan) data agar data dapat dipakai untuk melakukan peramalan. Adapun hasil pengujiannya dapat dilihat pada Tabel 2 .
Berdasarkan hasil uji dengan metode Levin, Lin \& Chu tersebut diketahui bahwa pengujian data stasioner adalah signifikan atau hipotesis nol yang menyatakan bahwa ada unit root pada kelima variabel ditolak. Hal ini dapat diartikan bahwa data untuk kelima variabel (DPS, dividend yield, ROA, leverage, dan PBV) adalah tidak ada unit root atau data bersifat stasioner. Dengan demikian tahap pengujian berikutnya dapat dilakukan.

Tabel 2: Hasil Uji Stasioner berdasarkan metode Levin, Lin dan Chu Variabel DPS, Dividend Yield, ROA, Leverage dan PBV

\begin{tabular}{lcccc}
\hline Variabel & Statistic & Prob. $^{{ }^{a}}$ & Cross-sections & Obs \\
\hline DPS & -1047724 & 0.0000 & 25 & 100 \\
Dividend Yield & -342.488 & 0.0000 & 25 & 100 \\
ROA & -11.7520 & 0.0000 & 25 & 100 \\
Leverage & -23.1267 & 0.0000 & 25 & 100 \\
PBV & -36.3035 & 0.0000 & 25 & 100 \\
\hline
\end{tabular}

Ket: ${ }^{a}=$ probabilitas Levin, Lin \& Chu test diasumsikan asymptotic normality 


\section{Memilih Model Regresi yang Terbaik Model pertama (Model regresi dengan Ordinary Least Square biasa)}

Model ini menggunakan pendekatan OLS dimana common intercept dan common coefficient digunakan untuk mengestimasi panel data. Model OLS ini layak digunakan bila konstanta atau intersepnya adalah sama untuk semua perusahaan (dengan syarat bahwa koefisien konstanta tidak signifikan). Adapun model dasar dan hasil estimasi model ini adalah sebagai berikut:

$$
\begin{aligned}
D_{P S S_{i t}=} & \beta_{1}+\beta_{2} D_{i t}+\beta_{3} R_{\text {ROA }}+\beta_{4} L_{E V} V_{i t} \\
& +\beta_{5} P_{B} V_{i t}+\mu_{i t}
\end{aligned}
$$

Tabel 3 ini menunjukkan hasil bahwa selama periode 2002-2006 dividend yield (DY), return on assets (ROA), dan leverage (LEV) mempengaruhi dividend per-share (DPS) secara signifikan untuk seluruh sampel (25 perusahaan). Hal ini dapat diartikan bahwa semakin tinggi dividend yield, return on assets, dan leverage maka semakin besar dividend pershare. Meskipun variabel leverage ini signifikan tetapi tanda dari koefisien ini tidak sesuai dengan hipotesis, berbeda halnya dengan variabel dividend yield dan return on assets yang signifikan dan tanda sesuai dengan hipotesis. Hasil ini tidak konsisten dengan penelitian sebelumnya (Alli et al, 1993; Jensen, 1986; dan Stulz, 1990). Sedangkan price- to- book value (PBV) tidak berpengaruh secara signifikan terhadap dividend per-share (meskipun tanda sesuai dengan hipotesis).

Meskipun tiga dari empat koefisien slope secara individu signifikan tetapi hasil estimasi menunjukkan bahwa nilai $R$-square kecil (0.246033). Berdasarkan nilai $R$ square yang kecil ini maka salah satu kriteria sebagai model yang baik tidak terpenuhi. Selain itu hasil estimasi juga menunjukkan bahwa nilai Durbin Watson (DW) rendah $(0,21242)$. Nilai DW yang rendah ini menunjukkan bahwa ada dugaan terdapat autokorelasi pada data. Dengan demikian model ini tidak lolos dari salah satu uji asumsi klasik regresi linier klasik. Oleh karena itu selanjutnya akan dicoba untuk menggunakan model berikutnya, yaitu fixed effect model, guna mendapatkan model yang lebih baik.

Tabel 3: Hasil Estimasi Panel Data: Pendekatan OLS

\begin{tabular}{ccccc}
\hline Variable & Coefficient & Std. Error & t-Statistic & Prob. \\
\hline C & -472.1024 & 201.4386 & -2.343654 & 0.0207 \\
DIV_YIELD? & 55.18509 & 10.67945 & 5.167409 & $\mathbf{0 . 0 0 0 0 ^ { * * * }}$ \\
ROA? & 3088.473 & 1000.721 & 3.086246 & $\mathbf{0 . 0 0 2 5 ^ { * * * }}$ \\
LEV? & 611.4435 & 321.7359 & 1.900451 & $\mathbf{0 . 0 5 9 8 ^ { * }}$ \\
PBV? & -30.83162 & 27.73604 & -1.111609 & 0.2685 \\
\hline R-squared & 0.246033 & F-statistic & & 9.789533 \\
Adjusted R-squared & 0.220901 & Prob(F-statistic) & & 0.000001 \\
Durbin-Watson stat & 0.212420 & & & \\
\hline Ket: & & &
\end{tabular}

\section{Ket:}

* $\quad=$ signifikan pada $\alpha=1 \%$

$* * *=$ signifikan pada $\alpha=10 \%$ 


\section{Model kedua (Fixed Effect Model)}

Model ini menggunakan pendekatan variabel boneka dimana fixed effect intercept dan common coefficient digunakan untuk mengestimasi panel data. Menurut Insukindro (2001: 151) fixed effect model ini menggunakan variabel boneka agar intersep dimungkinkan berubah bersama berjalannya waktu serta bersama unit lintas sektoral yang berbeda. Apabila slope juga berubah, dan setiap regresi lintas sektoral secara terpisah mempunyai model yang berbeda, maka model dengan variabel boneka tidaklah cocok diterapkan.

Adapun model dasar dan hasil estimasi model kedua disajikan sebagai berikut:

$$
\begin{aligned}
D_{P S} S_{i t}= & \alpha_{1}+\alpha_{2} D_{2 i}+\alpha_{3} D_{3 i}+\alpha_{4} D_{4 i} \\
& +\alpha_{5} D_{5 i}+\ldots+\alpha_{25} D_{25 i}+\beta_{2} D Y_{i t} \\
& +\beta_{3} R O A_{i t}+\beta_{4} L E V_{i t}+\beta_{5} P B V_{i t} \\
& +\mu \text { it }
\end{aligned}
$$

Keterangan:

$\alpha_{1} \quad=$ intersep perusahaan pembanding

$\mathbf{D}_{2} \ldots . . . \mathbf{D}_{25}=$ Dummy variable (variabel boneka) untuk 24 perusahaan, sedangkan sisanya, satu perusahaan ( $\mathbf{D}_{1}$ ) dipakai sebagai perusahaan pembanding (bebas untuk memilih perusahaan mana sebagai perusahaan pembanding)

$\mathbf{D}_{2 \mathbf{i}}$ diberi nilai 1, bila mengobservasi perusahaan 2, dan sebaliknya perusahaan lainnya diberi nilai $\mathbf{0} ; \mathbf{D}_{\mathbf{3 i}}$ diberi nilai $\mathbf{1}$, bila mengobservasi perusahaan 3 , dan sebaliknya perusahaan lainnya diberi nilai $\mathbf{0}$, dan seterusnya.

Tabel 4 menunjukkan hasil bahwa selama periode 2002-2006 untuk seluruh sampel (25 perusahaan) hanya dividend yield yang mempengaruhi DPS secara signifikan. Hal ini dapat diartikan bahwa semakin tinggi dividend yield untuk 25 perusahaan maka semakin besar DPS (dividen yang dibayarkan). Sedangkan ROA, leverage dan PBV untuk seluruh perusahaan tidak mempengaruhi DPS secara signifikan. Hasil ini tidak konsisten dengan hasil penelitian sebelumnya (Miller dan Modigliani, 1961; Alli et al, 1993; Jensen, 1986; Stulz, 1990; Brigham dan Gapenski, 1999; Jensen, 1986; Stulz, 1990). Namun bila dilihat dari perolehan $R$-squared menunjukkan angka yang lebih besar (0.922004) bila dibandingkan dengan model OLS (0.246033). Hal ini menunjukkan bahwa variasi variabel $\mathrm{Y}_{\mathrm{i}}$ yang mampu dijelaskan oleh variasi variabel $X_{i}$ semakin besar $(92,20 \%)$. Demikian pula dengan perolehan nilai DW yang semakin mendekati nilai sekitar 2 (1.501321), yang berarti dalam model ini tidak terdapat autokorelasi data. Dengan demikian model FE ini merupakan model penaksir yang lebih baik daripada model OLS berdasarkan nilai $R$-squared (memiliki goodness of fit) dan nilai DW.

Hasil estimasi pada Tabel 4 di bawah menunjukkan konstanta untuk seluruh sampel perusahaan berbeda-beda, antara lain konstanta perusahaan $1=$ 513.8704; perusahaan $2=-253.7182$; perusahaan $3=-316.8228$; perusahaan $4=-$ 149.1926 dan perusahaan $25=-174.6575$. Perbedaan konstanta (intersep) untuk masing-masing perusahaan ini dianggap wajar karena setiap perusahaan memiliki faktor spesifik yang berbeda seperti gaya manajerial (filosofi manajerial). Keunggulan model FE ini bila dibandingkan dengan model OLS adalah mampu mengungkapkan adanya perbedaan yang khas yang dimiliki setiap sampel perusahaan.

Setelah hanya ada satu faktor yang signifikan mempengaruhi DPS yaitu dividend yield dan adanya perbedaan faktor spesifik di setiap perusahaan maka dapat dianalisis jumlah dan jenis perusahaan yang memiliki kepekaan dividend yield dalam mempengaruhi DPS. Tabel 5 merupakan hasil estimasi panel data menggunakan fixed effect model secara spesifik untuk seluruh sampel selama periode pengamatan. 
Tabel 4:

Hasil Estimasi Panel Data: Fixed Effect Model

\begin{tabular}{|c|c|c|c|c|}
\hline Variable & Coefficient & Std. Error & t-Statistic & Prob. \\
\hline C & -118.1399 & 152.9445 & -0.772436 & 0.4418 \\
\hline DIV_YIELD? & 50.03610 & 5.003190 & 10.00084 & $0.0000^{* * *}$ \\
\hline ROA? & 626.4876 & 636.0138 & 0.985022 & 0.3271 \\
\hline LEV? & 236.1855 & 296.8944 & 0.795520 & 0.4283 \\
\hline PBV? & 10.55181 & 14.92040 & 0.707207 & 0.4812 \\
\hline Fixed Effects (Cross) & \multicolumn{4}{|c|}{ Fixed Effects (Cross) } \\
\hline$-1--C$ & -513.8704 & \multicolumn{2}{|c|}{ _14--C } & -66.71312 \\
\hline $2--C$ & -253.7182 & \multicolumn{2}{|c|}{ _15--C } & 68.19197 \\
\hline $3--C$ & -316.8228 & \multicolumn{2}{|c|}{ _16--C } & -249.0233 \\
\hline$-4--C$ & -149.1926 & \multicolumn{2}{|c|}{${ }_{-17--C}$} & 278.6067 \\
\hline -5--C & -201.5253 & \multicolumn{2}{|c|}{ _18--C } & 863.5897 \\
\hline -6--C & 2502.387 & \multicolumn{2}{|c|}{ _19--C } & -144.1897 \\
\hline _7--C & 156.0244 & \multicolumn{2}{|c|}{ _20--C } & -291.6698 \\
\hline _8--C & -146.3166 & \multicolumn{2}{|c|}{ _21--C } & -178.0210 \\
\hline _9--C & -178.5888 & \multicolumn{2}{|c|}{ _22--C } & -246.0133 \\
\hline _10--C & -221.0500 & \multicolumn{2}{|c|}{ _23--C } & -93.00878 \\
\hline _11--C & -265.0819 & \multicolumn{2}{|c|}{ 24--C } & -136.3831 \\
\hline _12--C & -11.46596 & \multirow{2}{*}{\multicolumn{2}{|c|}{ _25--C }} & -174.6575 \\
\hline$=13--C$ & -31.48775 & & & \\
\hline \multicolumn{5}{|c|}{ Effects Specification } \\
\hline \multicolumn{5}{|c|}{ Cross-section fixed (dummy variables) } \\
\hline R-squared & 0.922004 & \multicolumn{2}{|c|}{ F-statistic } & 40.52981 \\
\hline Adjusted R-squared & 0.899255 & \multirow{2}{*}{\multicolumn{2}{|c|}{ Prob(F-statistic) }} & 0.000000 \\
\hline Durbin-Watson stat & 1.501321 & & & \\
\hline
\end{tabular}

Ket: $* * *$ signifikan pada $\alpha=1 \%$ 
SIIERGH Vol. 10 No. 2, JUNI 2008: 157 - 169

Tabel 5:

Hasil Estimasi Panel Data: Fixed Effect Model

Variabel Dividend Yield Seluruh Sampel Periode 2002 - 2006

\begin{tabular}{|c|c|c|c|c|}
\hline Variable & Coefficient & Std. Error & t-Statistic & Prob. \\
\hline C & 56.85961 & 42.66115 & 1.332819 & 0.1857 \\
\hline _1--DIV_YIELD_1 & 10.88591 & 8.331004 & 1.306674 & 0.1944 \\
\hline _2--DIV_YIELD_2 & 3.706728 & 18.57652 & 0.199538 & 0.8423 \\
\hline _3--DIV_YIELD_3 & 36.52372 & 4.660200 & 7.837372 & $0.0000^{* * *}$ \\
\hline _4--DIV_YIELD_4 & -23.84295 & 66.32298 & -0.359497 & 0.7200 \\
\hline _5--DIV_YIELD_5 & -8.851909 & 34.81896 & -0.254227 & 0.7998 \\
\hline _6--DIV_YIELD_6 & 348.0622 & 12.78231 & 27.22999 & $0.0000^{* * *}$ \\
\hline _7--DIV_YIELD_7 & 96.97244 & 31.99563 & 3.030802 & $0.0031^{* * *}$ \\
\hline _8--DIV_YIELD_8 & 45.36595 & 41.07531 & 1.104458 & 0.2721 \\
\hline _9--DIV_YIELD_9 & -13.19178 & 34.99805 & -0.376929 & 0.7070 \\
\hline _10--DIV_YIELD_10 & -5.801158 & 25.42636 & -0.228155 & 0.8200 \\
\hline _11--DIV_YIELD_11 & 4.076276 & 14.25773 & 0.285899 & 0.7756 \\
\hline _12--DIV_YIELD_12 & 51.95640 & 27.20905 & 1.909526 & $0.0591^{*}$ \\
\hline _13--DIV_YIELD_13 & -121.1280 & 940.5061 & -0.128790 & 0.8978 \\
\hline _14--DIV_YIELD_14 & 6.435125 & 44.98007 & 0.143066 & 0.8865 \\
\hline _15--DIV_YIELD_15 & 56.80307 & 16.05650 & 3.537700 & $0.0006^{* * *}$ \\
\hline _16--DIV_YIELD_16 & -9.373395 & 27.99602 & -0.334812 & 0.7385 \\
\hline _17--DIV_YIELD_17 & 179.4789 & 21.73654 & 8.257012 & $0.0000^{* * *}$ \\
\hline _18--DIV_YIELD_18 & 217.1830 & 17.96022 & 12.09245 & $0.0000^{* * *}$ \\
\hline _19--DIV_YIELD_19 & 18.40832 & 16.20803 & 1.135753 & 0.2588 \\
\hline _20--DIV_YIELD_20 & 54.81761 & 43.98406 & 1.246306 & 0.2156 \\
\hline _21--DIV_YIELD_21 & -16.69787 & 50.59722 & -0.330016 & 0.7421 \\
\hline _22--DIV_YIELD_22 & 0.630084 & 19.18165 & 0.032848 & 0.9739 \\
\hline _23--DIV_YIELD_23 & 28.28953 & 12.63136 & 2.239626 & $0.0274^{* *}$ \\
\hline _24--DIV_YIELD_24 & -17.67869 & 46.74086 & -0.378228 & 0.7061 \\
\hline _25--DIV_YIELD_25 & 1.395099 & 32.69048 & 0.042676 & 0.9660 \\
\hline R-squared & 0.914686 & Mean dependent var & & 301.7600 \\
\hline Adjusted R-squared & 0.893142 & S.D. dependent var & & 674.9120 \\
\hline S.E. of regression & 220.6230 & Akaike info criterion & & 13.81359 \\
\hline Sum squared resid & 4818776. & Schwarz criterion & & 14.40188 \\
\hline Log likelihood & -837.3496 & F-statistic & & 42.45672 \\
\hline Durbin-Watson stat & 0.855770 & Prob(F-statistic) & & 0.000000 \\
\hline
\end{tabular}

Ket: $* * *=$ signifikan pada $\alpha=1 \%, * *=$ signifikan pada $\alpha=5 \%$

$*$ = signifikan pada $\alpha=10 \%$ 
Berdasarkan hasil estimasi terhadap variabel dividend yield untuk seluruh perusahaan selama periode pengamatan ditemukan ternyata hanya 8 dari 25 perusahaan memiliki koefisien yang signifikan secara statistik, baik pada $\alpha 1 \%, 5 \%$, maupun $10 \%$. Hal ini menunjukkan bahwa kepekaan dividend yield dalam mempengaruhi DPS dari 8 perusahaan tersebut lebih tinggi daripada 17 perusahaan lainnya. Ini dapat diartikan bahwa semakin besar variabel dividend yield dari 8 perusahaan tersebut maka semakin besar pula pengaruhnya terhadap pembayaran dividen yang dilakukan 8 perusahaan tersebut dibandingkan 17 perusahaan lainnya. Dengan demikian dapat disimpulkan bahwa variabel dividend yield secara signifikan berpengaruh positif terhadap DPS. Hal ini memberikan dukungan yang kuat untuk signalling theory. Semakin tinggi dividend yield yang dimiliki perusahaan menunjukkan sinyal yang positif bagi pasar karena perusahaan dianggap mampu membayarkan dividen yang lebih besar, terutama untuk 8 perusahaan tersebut.

Adapun kedelapan perusahaan tersebut adalah perusahaan $3,6,7,12,15$, 17, 18 dan 23. Sedangkan nama ke-8 perusahaan tersebut secara berurutan adalah sebagai berikut: 1) Tambang Timah, 2) Multi Bintang Ind., 3) Gudang Garam, 4) Surya Toto, 5) Goodyear Indonesia, 6) Kimia Farma, 7) Merck, dan 8) Rig Tenders. Meskipun kedelapan perusahaan ini memiliki koefisien yang signifikan tetapi semuanya bergerak di sektor usaha yang berbeda-beda, kecuali Kimia Farma dan Merck termasuk dalam satu kelompok usaha yang sama. Selain itu usia dan skala usaha dari 8 perusahaan tersebut juga berbeda. Hal inilah yang menyebabkan tingkat kepekaan explanatory variable terhadap dependent variable yang dimiliki setiap perusahaan berbeda-beda. Dengan demikian keunggulan dari model FE ini adalah mampu mengidentifikasi secara spesifik mengenai perusahaan yang memiliki koefisien variabel penjelas yang signifikan.

Berdasarkan hasil estimasi dari model FE menunjukkan bahwa variabel return on assets, leverage, dan price-to-book value secara signifikan tidak berpengaruh terhadap pembayaran dividen selama lima tahun untuk seluruh sampel perusahaan. Ketiga variabel ini tidak memberikan dukungan terhadap pecking order theory, agency theory, maupun residual dividend theory. Hasil temuan riset ini tidak konsisten dengan hasil beberapa studi lainnya (seperti Aharony \& Swary, 1980; Asquith \& Mullins, 1983; Pettit, 1972; Myers dan Majluf, 1984). Hal ini diduga bahwa ketiga variabel tersebut tidak relevan dalam menentukan kebijakan dividen perusahaan, khususnya di Indonesia, karena kebijakan dividen perusahaan di Indonesia lebih banyak ditentukan oleh sikap dan preferensi para pemegang saham yang tergabung dalam rapat umum pemegang saham (RUPS), bukan sekedar angka-angka yang tertera dalam laporan keuangan (bandingkan dengan penentu kebijakan dividen perusahaan di Amerika, yaitu Direksi).

\section{SIMPULAN DAN SARAN}

Studi ini menyimpulkan bahwa determinan kebijakan dividen untuk seluruh sampel perusahaan berdasarkan model OLS biasa adalah dividend yield, return on assets, dan leverage. Ketiganya berpengaruh secara signifikan terhadap pembayaran dividen, kecuali price-to-book value. Dengan demikian hasil riset berdasarkan model OLS tidak mendukung residual dividend theory. Sedangkan menurut FE model, sebagai determinan kebijakan dividen hanyalah dividend yield. Dividend yield memberikan pengaruh positif dan signifikan terhadap pembayaran dividen, khususnya hanya 8 perusahaan dari seluruh sampel perusahaan. Sedangkan $R O A$, leverage dan $P B V$ tidak 
mempengaruhi pembayaran dividen secara signifikan. Hal ini memberikan dukungan argumentasi bahwa ketiga variabel tersebut tidak relevan dalam menentukan kebijakan dividen perusahaan, khususnya di Indonesia.

Data yang digunakan dalam studi ini memenuhi syarat sebagai data yang stasioner. Model regresi untuk penelitian ini dicoba untuk diuji dengan menggunakan dua model regresi yaitu model regresi OLS biasa dan fixed effect model. Berdasarkan perbandingan hasil estimasi dari kedua model diketahui bahwa model yang lebih baik adalah fixed effect model. FE model lebih memiliki goodness of fit dibandingkan dengan model OLS biasa (dapat dilihat dari nilai $R$-squared yang semakin besar) dan nilai DW yang jauh dari indikasi adanya autokorelasi. Selain itu FE model juga mampu untuk mengungkapkan adanya perbedaan yang khas yang dimiliki setiap perusahaan, dan mampu untuk menganalisis perusahaan yang memiliki perbedaan kepekaan variabel dividend yield terhadap pembayaran dividen (dicerminkan dari tingkat signifikansinya).

\section{DAFTAR PUSTAKA}

Alli, Kassim L, Khan, A Qayyum \& Ramirez, Gabriel G. (1993). "Determinants of Corporate Dividend Policy: A Factorial Analysis." The Financial Review 28 (4): $523-547$

Baker, H. Kent \& Powell, Garry E. (2000). "Determinants of Corporate Dividend Policy: A Survey of NYSE Firms." The Financial Practice and Education: 29 - 40

Baker, H. Kent, Veit, E. Theoore \& Powell, Garry E. (2001). "Determinants of Corporate Dividend Policy: A Survey of Nasdaq Firms." The Financial Practice and Education: 29 - 40

Brigham, Eugene F., Gapenski, Louis C. \& Daves, Phillip R. (1999). Intermediate Financial Management. Sixth edition. USA: The Dryden Press.

Gujarati, Damodar R. (2003). Basic Econometrics. Fourth edition. McGrawHill International Edition.

Indonesian Capital Market Directory (2007). Institute For Economic \& Financial Research, edisi ke-8, Jakarta: ECFIN, 2007

Indonesian Capital Market Directory (2005). Institute For Economic \& Financial Research, edisi ke-8, Jakarta: ECFIN, 2005

Insukindro, Maryatmo, dan Aliman. (2001). Ekonometrika Dasar dan Penyususnan Indikator Unggulan Ekonomi. Modul Teori Pelatihan Ekonometrika. Makasar.

Jensen, Gerald R.; Solberg, Donald P.dan Zorn, Thomas S. (1992). "Simultaneous Determination of Insider Ownership, Debt and Dividend Policies." Journal of Financial and Quantitative Analysis 27 (2): 247 - 263

Jensen, M. C. (1986). "The Agency Costs of Free Cash Flow: Corporate Finance and Takeovers". American Economic Review 76: 323-9.

Miller, Merton dan Modigliani, F. (1961). "Dividend Policy, Growth and the Valuation of Shares." Journal of Business 34: 411-33. 
Naceur, Samy Ben, Goaied, Mohamed, dan Belanes, Amel. (2006). "On the Determinants and Dynamics of Dividend Policy". International Review of Finance 6: 1-23

Verbeek, M. (2004). A Guide to Modern Econometrics. John Wiley \& Sons, Ltd.

Stulz, R. M. (1990). "Managerial Discretion and Optimal Capital Structure." Journal of Financial Economics 26: 3-28 